\title{
Exploring how nurses assess, monitor and manage acute pain for adult critically ill patients in the emergency department: protocol for a mixed methods study
}

Wayne Varndell ${ }^{1,2^{*}}$, Margaret Fry ${ }^{2,3}$ and Doug Elliott ${ }^{2}$

\begin{abstract}
Background: Many critically ill patients experience moderate to severe acute pain that is frequently undetected and/or undertreated. Acute pain in this patient cohort not only derives from their injury and/or illness, but also as a consequence of delivering care whilst stabilising the patient. Emergency nurses are increasingly responsible for the safety and wellbeing of critically ill patients, which includes assessing, monitoring and managing acute pain. How emergency nurses manage acute pain in critically ill adult patients is unknown. The objective of this study is to explore how emergency nurses manage acute pain in critically ill patients in the Emergency Department.

Methods: In this paper, we provide a detailed description of the methods and protocol for a multiphase sequential mixed methods study, exploring how emergency nurses assess, monitor and manage acute pain in critically ill adult patients. The objective, method, data collection and analysis of each phase are explained. Justification of each method and data integration is described.

Discussion: Synthesis of findings will generate a comprehensive picture of how emergency nurses' perceive and manage acute pain in critically ill adult patients. The results of this study will form a knowledge base to expand theory and inform research and practice.
\end{abstract}

Keywords: Critically ill, Emergency department, Emergency nursing, Mixed methods, Pain, Protocol

\section{Background}

In Australia, the number of critically ill patients managed in the emergency department (ED) is increasing [1]. Between 2011 and 2016, the number of critically ill patients presenting to the ED increased by nearly $60 \%$ [2-4], with over a third of patients (39\%) needing intubation and mechanical ventilation [5]. Although care of critically ill patients traditionally occurs in intensive care units, emergency staff are increasingly having to manage critically ill mechanically ventilated patients for extended periods of time $[6,7]$. Pain management is an essential

\footnotetext{
* Correspondence: Wayne.Varndell@health.nsw.gov.au

'Prince of Wales Hospital Emergency Department, Randwick, NSW 2031, Australia

${ }^{2}$ Faculty of Health, University of Technology Sydney, Ultimo, NSW 2007,

Australia

Full list of author information is available at the end of the article
}

component of quality care delivery for the critically ill patient. However, as many as $79 \%$ of patients experience moderate to severe pain, whilst intubated and mechanically ventilated from both their initial reason for presentation (e.g. trauma) and required treatments [8]. Iatrogenic causes of pain include clinical procedures, physical examination, endotracheal intubation, mechanical ventilation, insertion of central venous catheters and chest drains; all of which commonly occur during resuscitation and stabilisation of a critically ill patient in the ED $[9,10]$. Intravenous analgesia is therefore commonly administered to alleviate pain, suffering, adverse physiological and psychological effects [11], unplanned self-extubation, accidental removal of invasive monitoring devices, or injury to staff $[7,10]$. 
Pain is a subjective, complex and multidimensional concept that is broadly described as an unpleasant sensory experience associated with actual or potential tissue damage [12], which can be influenced by psychological and environmental factors in every individual [13]. Thus, the most reliable and valid indicator of pain is the patient's self-report, yet for critically ill patients, communication of pain intensity is problematic; particularly for those with altered levels of consciousness, endotracheal intubation, requiring sedation, analgesia and potentially paralysing agents [14]. These factors therefore place the critically ill patient at greater risk of inadequate pain detection, assessment and inappropriate management [15]. In the absence of a patient's ability to self-report pain, clinicians usually rely on observable pain indicators such as facial grimacing, crying and compliance with mechanical ventilation. These observations then form the basis for identification and evaluation of a patient's pain intensity [16].

International pain management guidelines recommend frequent assessment, monitoring and reassessment, and use of validated instruments [11]. Historically, relief from pain through the provision of analgesia could only be initiated by a physician [17]. The shifting stance from physician-only initiated pain management to nurseinitiated analgesic protocols has significantly improved the timely delivery of care and symptom management of pain for a broad range of conditions in ED [18, 19]. A series of ED studies examining nurse-initiated analgesic protocols has demonstrated that emergency nurses can safely assess, initiate and administer analgesia to a range of patient groups and ambulatory conditions [17, 20-39], including the titration of intravenous opioids $[35,40]$.

In the resuscitation area of the ED, emergency nurses are increasingly responsible for the safety and wellbeing of critically ill patients, and are optimally placed to assess and initiate pain relief $[24,41]$. However, to date, how emergency nurses detect, assess, influence and manage acute pain for critically ill patients is unknown and has led to development of this research protocol. The objective of this mixed methods study is to examine emergency nurses' perceptions and practices in assessing and managing acute pain in critically ill patients. Specifically, to:

1. explore emergency nurses' practices relating to the assessment, monitoring and administration of analgesia to critically ill patients in ED;

2. examine care activities and behavioural patterns, actions, processes within the context of acute pain management;

3. identify factors, perceived facilitators, barriers and workplace characteristics that influence emergency nurses' practice in pain management of critically ill patients; and,
4. explore how emergency nurses influence pain management decisions or act independently with regards to the critically ill patient in the ED.

\section{Methods/design}

\section{Settings}

New South Wales (NSW) has the highest population of all states and territories in Australia. In 2016 there was 7.4 million people living in NSW encompassing an area of around $800,000 \mathrm{~km}^{2}$ [42]. Of the 186 public EDs in NSW, 25 are situated within major referral hospitals with capabilities to manage a wide range of highly complex emergency and critical care; 10 of which are designated state trauma centres. In 2016, there were 2.7 million ED presentations in NSW, of which critically ill or injured patients with lifethreatening conditions, defined as patients triaged category 1 or 2 using the Australasian Triage Scale (ATS), represented over one-third $(n=966,560$; $34.8 \%)$ of all presentations [2]. Of the 334,112 (34.6\%) critically ill patients that had presented to NSW EDs, most $(n=49,069 ; 14.7 \%)$ had presented to a major referral ED; less than $2 \%(n=3970 ; 1.2 \%)$ were major trauma related [43].

\section{Design}

Emergency healthcare occurs across a complex sequence of complex interactions that are difficult to assess with strictly quantitative or qualitative research methods. Thus, an explanatory sequential mixed-methods (quan $\rightarrow$ QUAL $\rightarrow$ QUAL) research design will be conducted in three phases, comprising a survey, observations and semi-structured face-to-face interviews. The study process is outlined in Fig. 1.

To address aims 1, 3 and 4, Phase 1 will use a Delphi technique to develop survey items exploring core outcome variables to measure adequate management of acute pain in critically ill adult patients. The final survey will be administered through a Web-based platform to emergency nurses in NSW. The purpose of the questionnaire is threefold: to enhance the descriptive results of observations and interviews, to validate corresponding observations and statements, and to compare emergency nurses' perceptions on managing acute pain in critically ill adult patients. Addressing aims 2 and 3, Phase 2 will observe consenting emergency nurses managing critically ill patients in the resuscitation area, specifically behaviours and interactions in detecting, assessing and managing acute pain. To address aims 1, 3 and 4, Phase 3 will interview consenting emergency nurses about their experiences and practices in managing acute pain in critically ill patients. Donabedian's Quality and Safety model [44], as extended by Coyle and Battles [45], will be used to analyse information obtained in the study. 


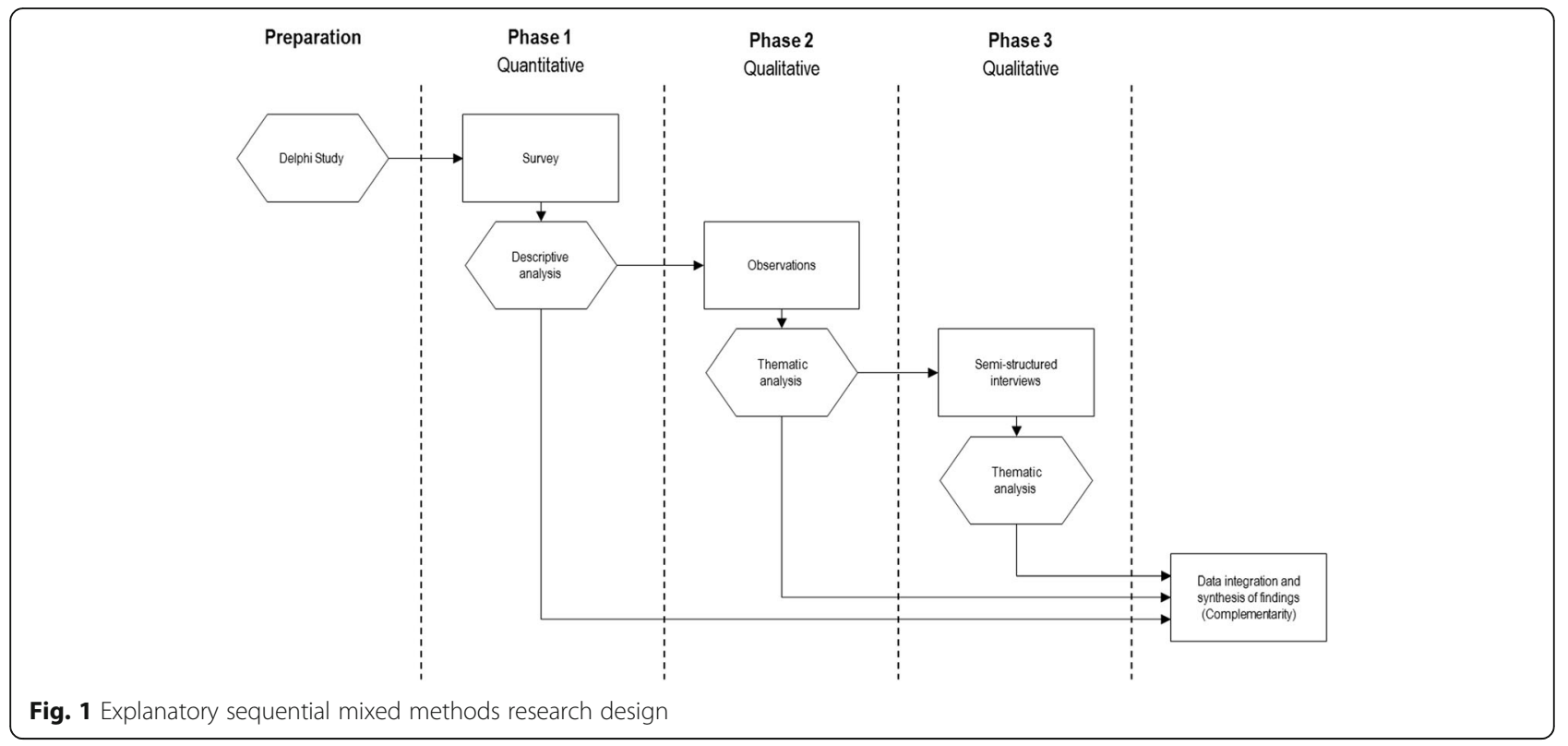

The model provides a framework for examining health services and evaluating quality of health care, including examining clinical practice in healthcare [46], clinician communication [47] and advanced nursing practice [48]. The framework is comprised of four elements: antecedents, structure, process and outcome (Table 1).

\section{Sampling, recruitment and consent Survey participants}

Recruitment of survey participants will be initially conducted through the College of Emergency Nursing Australasia, which represents over 1400 emergency nurses across Australia. Members of the College will be provided by email and via College social media platforms, information concerning the nature and purpose of the study and a private link to the electronic survey. Nurses working in a NSW ED who have care for critically ill (ATS category 1

Table 1 Expanded Donabedian's quality care framework

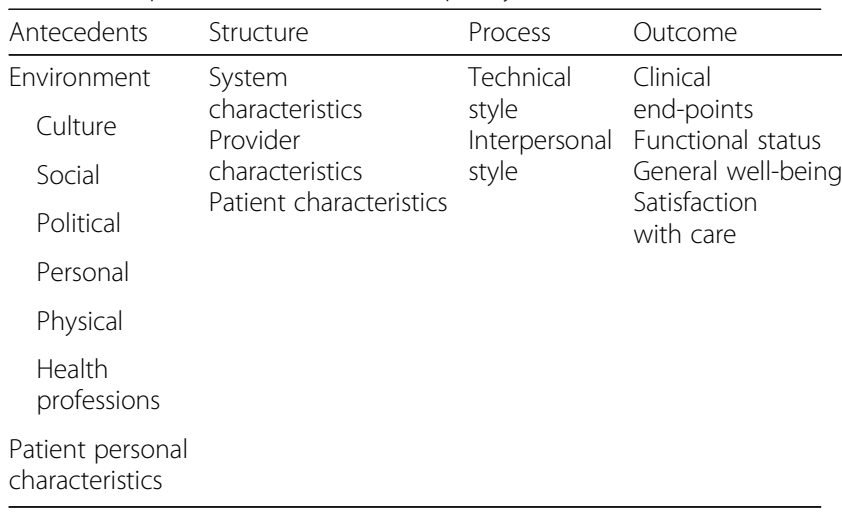

or 2) adult ( $\geq 16$ years old) patients in the last six months will be eligible for participation.

\section{Observation participants}

Two designated trauma EDs will be randomly selected and approached to seek permission to conduct observations of emergency nurses managing critically ill patients in the resuscitation area. Trauma designated EDs typically manage high volumes of critically ill patients and have the most exposure to managing acute pain in this cohort of patients. Study information will be distributed and discussed at departmental meetings. All emergency nurses able to work in the resuscitation area will be invited to take part in the observation study. Written informed consent will be obtained from nursing staff who agree to participate. The researcher will observe consenting emergency nurses working in the resuscitation area managing any adult ( $\geq 16$ years old) critically ill patients triaged category 1 or 2 .

\section{Interview participants}

Once observations have been completed and saturation reached, emergency nurses at the two observation sites will be invited to participate in a face-to-face interview. All emergency nurses with four or more years' clinical experience of working in the resuscitation area and who have recently managed a critically ill patient triaged category 1 or 2 within the last six months will be eligible for participation. Written informed consent will be obtained from nursing staff who agree to participate.

\section{Data collection}

There are three sources of data collection. 


\section{Phase 1: Survey}

There is an absence of empirical data concerning nursing pain assessment and management of critically ill patients in the ED. Consequently, a Delphi technique will be used to develop survey items exploring emergency nurses' practices in managing acute pain in critically ill patients. The Delphi technique is a method for achieving convergence of opinion concerning real-world knowledge solicited from experts within certain topic areas, and is in keeping with a mixed-methods framework [49]. The Delphi will consist of an expert panel of seven emergency nurse specialists from metropolitan and regional EDs. Studies employing the Delphi technique make use of individuals who have knowledge and experience of the topic being investigated [49]. As nursing role titles and descriptions vary across Australia, the following inclusion criteria will be applied: i) Registered Nurse; ii) currently working in an ED; iii) holds a postgraduate qualification in emergency nursing or greater; iv) has over five years clinical experience; and, v) is Clinical Nurse Consultant or Nurse Educator.

Consensus level needed to be reached following stability ( $<15 \%$ variation between rounds) [50] will be $85 \%$ (6 out of 7 panel members). It is anticipated that the Delphi study will consist of three rounds, with the preliminary question being: what are the core outcome variables to measure adequate management of acute pain in critically ill adult patients? The final survey will be administered through a secure Web-based platform. Emergency nurses working in a NSW ED who have contact with critically ill (ATS category 1 or 2 ) adult ( $\geq 16$ years old) patients in the last six months will be invited to participate. Electronic reminders will be sent at 3 and 6 weeks after the initial invite. A link will be provided for participants to further disseminate the survey (i.e. snowballing) [51].

\section{Phase 2: Observation}

The second phase of data collection will comprise observations by the primary author (WV) as a non-participant observer in the resuscitation area of two NSW trauma designated EDs. Observations will be recorded as field notes to capture understandings of how emergency nurses detect, assess and manage acute pain in critically ill patients in everyday practice [52]. There are a lack of studies using observation to identify nurse-initiated analgesia, its safety and impact on patient outcomes; most data collection techniques have included survey/questionnaire $[35,39,53]$, interview $[37,54,55]$ or audits $[21,24,36,37,39,56-58]$. These methods however reflect only reported, not observed actual practice. Undertaking observations of emergency nurses' behaviours and interactions when delivering care to critically ill patients will add an outsider perspective to capture activities, processes, practice behaviours and context [59].
The non-participant observer (WV) will first introduce themselves to clinicians present in the resuscitation area. The study will be described in general terms as an observational study into how nurses manage critically ill patients. The specific details of data to be collected will be omitted to avoid unduly influencing nurse performance. Written informed consent will then be obtained. The researcher will then position themselves in such a way to observe but not obstruct emergency nurses or other members of the care team in their work. While openness is emphasised in qualitative inquiry, the observer will use an observation guide to assist field note recording of observations in such a complex sociotechnical setting [60] (Table 2).

Observation sessions will continue until data saturation has been achieved and observed instances become repetitive [59]. Up to four weeks of observation (80-100 h) will be conducted in order to observe emergency nurses $(n=8-15)$ and critically ill patients $(n=18-25)$. This proposed period of time will allow sufficient opportunity to observe a wide variety of critically ill patients being managed in the resuscitation area, build trust and enable the observer to learn and understand the way emergency nurses' practice in the everyday world [61].

\section{Phase 3: Semi-structured interviews}

In Phase 3, in-depth, semi-structured face-to-face interviews will be conducted by the lead researcher (WV) with a sample of emergency nurses $(n=10$ to15) from the observation study sites. The purpose of face-to-face

Table 2 Observation guide

\begin{tabular}{|c|c|}
\hline $\begin{array}{l}\text { Observation } \\
\text { dimension }\end{array}$ & Description \\
\hline Space & $\begin{array}{l}\text { The positioning of the resuscitation area } \\
\text { in relation to the department, the overall } \\
\text { physical layout of the resuscitation area } \\
\text { and bed space }\end{array}$ \\
\hline Activity & $\begin{array}{l}\text { Movement, interaction or a set of } \\
\text { interrelated actions that occur between } \\
\text { emergency nurses and/or other healthcare } \\
\text { providers }\end{array}$ \\
\hline Act & $\begin{array}{l}\text { A single action undertaken by an } \\
\text { emergency nurse or care team member }\end{array}$ \\
\hline Time & $\begin{array}{l}\text { A particular point, period in time, pace } \\
\text { or order of event that occur }\end{array}$ \\
\hline Actor & Range of healthcare clinicians \\
\hline Object & $\begin{array}{l}\text { The type, arrangement of physical things } \\
\text { that are present }\end{array}$ \\
\hline Event & $\begin{array}{l}\text { Activities that emergency nurses carry out, } \\
\text { respond to }\end{array}$ \\
\hline Goal & Things that emergency nurses set to accomplish \\
\hline
\end{tabular}


interviews will be to explore clinical experiences, feelings, attitudes and opinions that cannot be observed or easily shared in a group setting, and identify tacit skills and complexities embedded in the practice of managing acute pain in the critically ill patient [62]. Thus, they are a complementary method and serve as an additional data source of information. Interviews have been chosen as the last study phase to exclude any potential influence on responses to the survey or behaviour during observations, by raising awareness of emergency nurses' practices in managing acute pain in critically ill patients.

An interview schedule will be informed by the survey (Phase 1) and observation (Phase 2) findings, and extant literature. Interviews will enable clarification and insight into the experiences, practice, decision-making, barriers and facilitators in managing acute pain in critically ill adult patients in the ED. Participants will be interviewed in a private area close to the clinical area for their convenience. All interviews will be audio-recorded and transcribed soon after recording to support data immersion and understanding of what has been said [63].

\section{Data analysis and integration Quantitative data analysis}

Survey data will undergo exploratory analysis to describe and identify consistencies or inconsistencies that might impact on the validity of the data findings. Appropriate descriptive statistics will be used to summarise data pertaining to individual variables, considering each variable's level of measurement and the observed distribution of its data. Data will be analysed using IBM SPSS Statistics ${ }^{\circ} 24.0$ [64], with a $p$-value of $<0.05$ considered significant. Data distribution will be assessed via Q-Q-Plot, histograms generated and frequencies and percentages calculated. Depending upon the distributional properties of the measures, appropriate tests and analyses will be applied (e.g. ANOVA, Mann-Whitney, chi-square testing, Pearson's correlation coefficient).

\section{Qualitative data analysis}

Descriptive statistics will be used to summarise demographic data collected from participants. Observations and interview audio recordings will be transcribed into text files and then imported into $\mathrm{NVivo}^{\text {Tx }}$ [65] for data management. The analytic process will be supported by Braun and Clarke's [66] analysis framework. First, the researcher will familiarise themselves with the data by comparing field notes and audio-recordings during transcription. Second, a two-step process will be undertaken to generate initial codes. Initially, textual data will be reduced into smaller units: groups of words, sentences or paragraphs that contained particular aspects related to explore the research question. Each data segment will then be coded according to the essence identified from the unit of the data. Third, the researcher will cluster the codes to begin pattern generation and theme development. Theme development will be informed by the patterns and categories. After codes are categorised, the research team will review each cluster of codes to confirm patterns and meaning that accurately connect and express the data and thereby confirm themes [67]. Finally, themes and patterns pertaining to assessing and managing acute pain in critically ill adult patients by emergency nurses will be examined in relation to the underlying structure of Donabedian's quality and safety model [45] and existing literature.

\section{Mixed methods data integration and analysis}

The integration and analysis of quantitative and qualitative data is what strengthens and gives richness to a mixed methods study [68]. Data integration and analysis within sequential explanatory mixed methods design occurs once all phases have been completed [69]. One of the most common purposes for mixing methods is complementarity, whereby quantitative and qualitative methods are used in a complementary fashion to answer related questions for the purpose of gaining a broader and more comprehensive understanding of the phenomenon [70]. Data transformation will further assist with quantitative and qualitative data integration [68]. In this study, quantitative data will first be presented in tables and histograms, with qualitative data displayed using charts (i.e. joint display) [71]. Second, quantitative data will then be qualitized through modal profiling [72], with narratives generated around the most frequently (i.e. modal) reported characteristics and practices in providing acute pain relief to critically ill patients. Third, qualitative data will be quantitized by transforming qualitative codes into numeric counts and variables [73]. Following data transformation, the transformed study data will be combined into a new data set. Lastly, to obtain a comprehensive description of the phenomena under investigation, the research team will then compare and contrast the quantitative data with quantitized qualitative data, and the qualitative data with the qualitized quantitative data; producing blended variables and meta-inferences [74]. To enhance the study rigour and validity of mixed methods research findings, the unified validation framework [75] for mixed methods research will be used. Consideration of strategies to meet criteria for validity is integral to building an optimal mixed-methods study design. A number of strategies [68, 76-78] have been described (Table 3).

\section{Ethical considerations}

All data will be collected, managed, analysed and stored in accordance with national ethical and scientific quality standards [79]. Participation in any part of this study will be voluntary; participants have the right to withdraw 
Table 3 Unified Validation Framework, strategies to improve validity of mixed-methods research

\begin{tabular}{|c|c|}
\hline Component, definition & Strategies \\
\hline $\begin{array}{l}\text { Foundational element, researchers' knowledge of the } \\
\text { phenomenon of interest, methodology }\end{array}$ & Detailed critique and description of the surrounding literature $[1,7,83,84]$ \\
\hline $\begin{array}{l}\text { Design quality, appropriateness of methods and data } \\
\text { analysis techniques in answering the research question }\end{array}$ & $\begin{array}{l}\text { In-depth description and rationale for research design, methods, data analysis and } \\
\text { integration choices with reference to the extant literature } \\
\text { Piloting of survey, observation and interview guide to insure accuracy and feasibility } \\
\text { (internal validity) } \\
\text { Use of multiple data sources to increase depth of understanding } \\
\text { (dependability, reliability) } \\
\text { Use of eligibility criteria and purposive sampling to ensure information-rich } \\
\text { participants and observations. } \\
\text { Prolonged engagement with the field/participants to ensure depth of understanding, } \\
\text { reduce Hawthorn effect and to build trust (internal validity) } \\
\text { Auditing of transcripts to ensure accuracy (dependability, reliability) } \\
\text { Detailed, thick descriptive data (e.g. direct quotes) to assist reader interpretation and } \\
\text { understanding of context (transferability, external validity) } \\
\text { Use of reflective diary to recall decisions made, thoughts, feelings, instincts and } \\
\text { challenges (confirmability, objectivity) }\end{array}$ \\
\hline $\begin{array}{l}\text { Legitimation, collection and integration of quantitative } \\
\text { and qualitative data }\end{array}$ & $\begin{array}{l}\text { Participant-driven data collection } \\
\text { Use of and detailed description of complementarity framework in integrating } \\
\text { quantitative and qualitative data } \\
\text { Peer review/research team triangulation - coding, interpretation and generation of } \\
\text { inferences } \\
\text { Audit trail of decision-making and rationale throughout data collection, analysis and } \\
\text { integration processes (dependability, reliability) }\end{array}$ \\
\hline $\begin{array}{l}\text { Interpretive rigor, whether the meta-inference adequately } \\
\text { incorporates inferences stemming from integrated data }\end{array}$ & $\begin{array}{l}\text { Peer review/research team driven generation of meta-inferences } \\
\text { Audit trail of decision-making and rationale in generating of meta-inferences; data } \\
\text { used, source(s) and weight within meta-inference }\end{array}$ \\
\hline $\begin{array}{l}\text { Inferential consistency, relationship between findings and } \\
\text { prior understandings, research and theory }\end{array}$ & $\begin{array}{l}\text { Detailed discussion of study findings and relationship to extant literature and } \\
\text { theory - highlighting consistencies and discrepancies }\end{array}$ \\
\hline $\begin{array}{l}\text { Utilisation / Historical element, how integrated data was } \\
\text { used }\end{array}$ & Audit trail of decision-making and rationale in selection of data used \\
\hline $\begin{array}{l}\text { Consequential element, acceptability of findings, or } \\
\text { inferences of a study }\end{array}$ & $\begin{array}{l}\text { Peer-reviewed publications } \\
\text { Diverse range of participants } \\
\text { Strengths, limitations and challenges described in detail }\end{array}$ \\
\hline
\end{tabular}

their consent and data at any time. All data will be deidentified prior to analysis. Phase 1 of this study protocol was approved by the South Eastern Sydney Human Research and Ethics Committee (17/162). Given the sequential nature of the study phases, with findings from one phase informing the development of the next, ethical approval will also be sought consecutively for each phase.

\section{Discussion}

This will be the first comprehensive, integrated mixedmethods study to examine emergency nurses' practices in assessing, monitoring and managing acute pain in critically ill patients. Emergency nurses undertake numerous clinical activities, often simultaneously or for multiple critically ill patients while working within the resuscitation area. The degree of knowledge and skills required to optimise and safely manage critically ill patients is highly complex, including acute pain management [7]. Adequate pain management is paramount in optimising comfort, pain relief and wellbeing of critically ill or injured patients. International guidelines concerning effective acute pain management recommend adequate assessment in all patients, with practice systems in place to ensure appropriate and timely analgesia assessment, and frequent monitoring and reassessment [11, 80, 81]. Emergency nurses are optimally placed to assess and initiate pain relief $[24,41]$, however the complexity of emergency nursing practice, judgment and factors influencing the detection, assessment and management of pain for critically patients is unknown. This study will provide answers to addressing a critical knowledge/practice gap in the science of emergency nursing, practice and literature regarding the assessment and management of pain in critically ill adult patients in ED.

The incorporation of Donabedian's expanded quality and safety model [45] into the data collection and analysis, including the examination of factors influencing the clinical decisions and actions of emergency nurses, will develop a clearer understanding of what must be addressed to optimise acute pain management of critically ill patients in the ED. The systematic inquiry into 
the clinical environment (Antecedents) and model of care (Structure), the actions and interactions of emergency nurses in managing acute pain (Process), and, their influence in managing acute pain in critically ill or injured patients (Outcome), will assist this study to produce meaningful, practical and measurable recommendations concerning practice, education and policy.

\section{Strengths and limitations}

This study has several strengths, including its robust and straightforward design. Using a sequential explanatory mixed methods study design will enable rich exploration of the existing practice of emergency nurses in assessing, monitoring and managing acute pain in critically ill adult patients. The use of quantitative and qualitative methods and integration of data will provide the research team with multiple perspectives from which to understand the complex and multidimensional nature of nursing practice and pain management in the ED.

There are several potential limitations that need to be considered. Sequential mixed methods studies are time-consuming to undertake, but it is felt that the richness of data obtained makes this an appropriate approach. Recruiting eligible survey participants will be engaged through email, web-based and other indirect methods of information dissemination. Consequently, emergency nurses who did not have reliable access to the Internet or membership to the College of Emergency Nursing Australasia may be excluded from participation. Strategies have been proposed to limit the impact of this and to increase survey response rate [51].

Observations and interviews will be undertaken in two trauma designated EDs, which may limit transferability of study findings. In undertaking observations and interviews in two large trauma designated ED facilities, it will increase the number and diversity in demographic characteristics of emergency nurses and critically ill patients; thereby developing a deeper understanding of how emergency nurses manage acute pain across a wide spectrum of critically ill patients, and increase transferability and generalisability of the study findings.

In observing emergency nurses within the clinical environment, nurses may demonstrate an increased awareness in assessing, monitoring and communicating with their patients about their comfort and therefore pain because of being observed. Strategies have been highlighted to address this issue. In additional, it has also been demonstrated previously that it is difficult for individuals to sustain behaviour that is dramatically different from normal for any length of time in a busy health care environment [82].

\section{Conclusion}

This protocol outlines a multiphase sequential explanatory mixed methods study that will guide investigation of emergency nurses' perceptions and practices in assessing and managing acute pain in critically ill adult patients. Outcomes of this study will provide urgently needed insight into knowledge gaps on how acute pain is managed in critically ill patients in the ED, how barriers are overcome and what resources are required to facilitate optimal patient care and safety. These findings will serve as a knowledge base to expand theory and inform research and practice in this important and evolving area of emergency practice.

\section{Acknowledgments \\ Not applicable.}

Availability of data and supporting materials

Data sharing not applicable to this article as no datasets were generated or analysed during the current study.

Ethical approval and consent to participate Not applicable.

\section{Funding}

This paper did not receive any funding from any source.

\section{Authors' contributions}

W wrote the first draft of the paper; all other authors contributed to development of the study protocol and writing of this manuscript. All authors read and approved the final manuscript.

Consent for publication

Not applicable.

\section{Competing interests}

The authors declare that they have no competing interests.

\section{Publisher's Note}

Springer Nature remains neutral with regard to jurisdictional claims in published maps and institutional affiliations.

\section{Author details}

${ }^{1}$ Prince of Wales Hospital Emergency Department, Randwick, NSW 2031, Australia. 'Faculty of Health, University of Technology Sydney, Ultimo, NSW 2007, Australia. ${ }^{3}$ Director Research and Practice Development Nursing and Midwifery Directorate NSLHD, Level 7 Kolling Building, Royal North Shore Hospital, St Leonards, NSW 2065, Australia.

Received: 8 June 2017 Accepted: 26 July 2017

Published online: 01 August 2017

\section{References}

1. Varndell W, Elliott D, Fry M. Emergency nurses' practices in assessing and administering continuous intravenous sedation for critically ill adult patients: a retrospective record review. Int Emerg Nurs. 2015;23(2):81-8.

2. Australian Institute of Health and Welfare. Emergency department care: Australian hospital statistics 2015-16. In: Health services series no. 72. Cat no. HSE 182. Canberra: AlHW: 2016.

3. Australian Institute of Health and Welfare. Australian hospital statistics 2010-11. In: Health services series no. 43. Cat no. HSE 117. Canberra; 2012.

4. $A C T$ Government. ACT public health services quarterly performance report. Canberra: Department of Health; 2016.

5. Australian Institute of Health and Welfare. Admitted patient care 2013-14: Australian hospital statistics. In: Health services series no. 60. Canberra: AlHW; 2015. 
6. O'Connor G, Geary U, Moriarty J. Critical care in the emergency department. Eur J Emerg Med. 2009;16:296-300.

7. Varndell W, Elliott D, Fry M. Assessing, monitoring and managing continuous intravenous sedation for critically ill adult patients and implications for emergency nursing practice: a systematic literature review. Australas Emerg Nurs J. 2015;18(1):1-23.

8. Ma P, Liu J, Xi X, Du B, Yuan X, Lin H, et al. Practice of sedation and the perception of discomfort during mechanical ventilation in Chinese intensive care units. J Crit Care. 2010;25(3):451-7.

9. National Health and Medical Research Council. Emergency care acute pain management manual. Canberra: NHMRC; 2011.

10. Weir S, O'Neill A. Experiences of intensive care nurses assessing sedation/ agitation in critically ill patients. Nurs Crit Care. 2008;13(4):185-94.

11. Schug S, Palmer G, Scott D, Halliwell R, Trinca J, APM:SE Working Group of the ANZCA and Faculty of Pain Medicine. Acute pain management: scientific evidence. In: Australian and new Zealand College of Anaesthetists and faculty of pain medicine. 4th ed; 2015. p. 714.

12. International Association for the Study of Pain. Pain terminology. Seattle: IASP; 2006.

13. Loeser J, Treede R. The Kyoto protocol of ISAP basic pain terminology. Pain. 2008:3:473-7.

14. Jacobi J, Fraser GL, Coursin D, Riker RR, Fontaine D, Wittbrodt E, et al. Clinical practice guidelines for the sustained use of sedatives and analgesics in the critically ill adult. Crit Care Med. 2002;30:119-41.

15. Puntillo K, Pasero C, Li D, Mularski R, Grap M, Erstad B, et al. Evaluation of pain in ICU patients. Chest. 2009;135:1069-74.

16. Herr K, Coyne P, McCaffery M, Manworren R, Merkel S. Pain assessment in the patient unable to self-report: position statement with clinical practice recommendations. Pain Manag Nurs. 2011;12(4):230-50.

17. Taylor D, Bennett D, Cameron P. Paradigm shift in the nature of care provision in emergency departments. Emerg Med J. 2004;21(6):681-4.

18. Fry $\mathrm{M}$, Jones $\mathrm{K}$. The clinical initiative nurse: extending the role of the emergency nurse, who benefits? Australas Emerg Nurs J. 2005;8(1-2):9-12.

19. Varndell W, Ryan E, Jeffers A, Marquez-Hunt N. Emergency nursing workload and patient dependency in the ambulance bay: a prospective study. Australas Emerg Nurs J. 2016;19(4):210-6.

20. Arendts $\mathrm{G}$, Fry M. Factors associated with delay to opiate analgesia in emergency departments. J Pain. 2006;7(9):682-6.

21. Fry M, Holdgate A. Nurse-initiated intravenous morphine in the emergency department: efficacy, rate of adverse events and impact on time to analgesia. Emerg Med (Fremantle). 2002;14(3):249-54.

22. Fry M, Ryan J, Alexander N. A prospective study of nurse initiated panadeine forte: expanding pain management in the ED. Accid Emerg Nurs. 2004;12(3):136-40.

23. Todd K, Ducharme J, Choiniere M, Crandall C, Fosnocht D, Homel P, et al. Pain in the emergency department: results of the pain and emergency medicine initiative (PEMI) multicentre study. J Pain. 2007;8:460-6.

24. Finn J, Rae A, Gibson N, Swift R, Watters T, Jacobs I. Reducing time to analgesia in the emergency department using a nurse-initiated pain protocol: a before-and-after study. Contemp Nurse. 2012;43(1):29-37.

25. Pines J, Hollander J. Emergency department crowding is associated with poor care for patients with severe pain. Ann Emerg Med. 2008;51(1):1-5.

26. Tanabe $P$, Buschmann M. A prospective study of ED pain management practices and the patient's perspective. J Emerg Nurs. 1999;25(3):171-7.

27. Nelson BP, Cohen D, Lander O, Crawford N, Viccellio AW, Singer AJ. Mandated pain scales improve frequency of ED analgesic administration. Am J Emerg Med. 2004;22(7):582-5.

28. Doherty S, Knott J, Bennetts S, Jazayeri M, Huckson S. National project seeking to improve pain management in the emergency department setting: findings from the NHMRC-NICS National Pain Management Initiative. Emerg Med Australas. 2013;25(2):120-6.

29. Steinberg PL, Nangia AK, Curtis K. A standardized pain management protocol improves timeliness of analgesia among emergency department patients with renal colic. Qual Manag Health Care. 2011;20(1):30-6

30. Todd KH, Ducharme J, Choiniere M, Crandall CS, Fosnocht DE, Homel P, et al. Pain in the emergency department: results of the pain and emergency medicine initiative (PEMI) multicenter study. J Pain. 2007;8(6):460-6.

31. Ducharme J, Tanabe P, Homel P, Miner JR, Chang AK, Lee J, et al. The influence of triage systems and triage scores on timeliness of ED analgesic administration. Am J Emerg Med. 2008;26(8):867-73.
32. Forero R, Mohsin M, McCarthy S, Young L, leraci S, Hillman $K$, et al. Prevalence of morphine use and time to initial analgesia in an Australian emergency department. Emerg Med Australas. 2008;20(2):136-43.

33. Kelly AM, Brumby C, Barnes C. Nurse-initiated, titrated intravenous opioid analgesia reduces time to analgesia for selected painful conditions. CJEM. 2005;7(3):149-54.

34. Newton-Brown E, Fitzgerald L, Mitra B. Audit improves emergency department triage, assessment, multi-modal analgesia and nerve block use in the management of pain in older people with neck of femur fracture. Australas Emerg Nurs J. 2014;17(4):176-83.

35. Muntlin A, Carlsson M, Safwenberg U, Gunningberg L. Outcomes of a nurseinitiated intravenous analgesic protocol for abdominal pain in an emergency department: a quasi-experimental study. Int J Nurs Stud. 2011;48(1):13-23.

36. Fry M, Bennetts S, Huckson S. An Australian audit of ED pain management patterns. J Emerg Nurs. 2011;37(3):269-74.

37. Shaban RZ, Holzhauser K, Gillespie K, Huckson S, Bennetts S. Characteristics of effective interventions supporting quality pain management in Australian emergency departments: an exploratory study. Australas Emerg Nurs J. 2012;15(1):23-30.

38. Gorman V, Considine J, Pane M, Middleton F. Clinical initiatives nurse: role redesign to improve ambulance emergency department interface. Australas Emerg Nurs J. 2011;14:S19.

39. Muntlin Athlin A, Carlsson M, Gunningberg L. To receive or not to receive analgesics in the emergency department: the importance of the pain intensity assessment and initial nursing assessment. Pain Manag Nurs. 2015; 16(5):743-50.

40. Kelly A, Brumby C, Barnes C. Nurse initiated, titrated intravenous opioid analgesia reduces time to analgesia for selected painful conditions. Can J Emerg Med. 2005;7(3):149-54.

41. Fry $M$, Holdgate A. Nurse initiated intravenous morphine in the emergency department: efficacy, rate of adverse events and impact on time to analgesia. Emerg Med Australas. 2002;14(3):249-54.

42. Australian Bureau of Statistics. 2016 Census Community Profiles. ABS; 2017.

43. NSW Institute of Trauma and Injury Management. Major trauma in NSW, 2015: a report from the NSW trauma registry. 2015 [cited 2017 June]; Available from: https://www.aci.health.nsw.gov.au/_data/assets/pdf_file/ 0007/341098/Major_Trauma_in_NSW,_2015._A_Report_from_the_NSW_ Trauma_Registry_Final.pdf.

44. Donabedian A. Explorations in quality assessment and monitoring: the definition of quality and approaches to its assessment. Ann Arbor: Health Administration Press; 1980.

45. Coyle Y, Battles J. Using antecedents of medical care to develop valid quality of care measures. Int J Qual Health Care. 1999;11(1):5-12.

46. Battles J, Lilford R. Organizing patient safety research to identify risks and hazards. Qual Saf Health Care. 2003;12(Suppl 2):2-7.

47. Sayer M. Improving collaboration and patient safety by encouraging nurses to speak-up: overcoming personal and organizational obstacles through self-reflection and collaboration. University of California: ProQuest Dissertations \& Thesis; 2010. p. 200.

48. Gardner G, Gardner A, O'Connell J. Using the Donabedian framework to examine the quality and safety of nursing service innovation. J Clin Nurs. 2014;23(1-2):145-55.

49. Keeney S, Hasson F, McKenna $\mathrm{H}$. The Delphi technique in nursing and health research. Ames: Wiley-Blackwell; 2011.

50. Scheibe M, Skutsch M, Schofer J. Experiments in Delphi methodology. In: Linstone $H$, Turoff M, editors. The Delphi method - techniques and applications. Reading: Addison-Wesley; 1975. p. 262-87.

51. Nulty DD. The adequacy of response rates to online and paper surveys: what can be done? Assess Eval High Educ. 2008;33(3):301-14.

52. Polit D, Totana Beck C. Essentials of nursing research: appraising evidence for nursing practice. 6th ed. Philadelphia: Lippincott Williams \& Wilkins; 2010.

53. Hadorn F, Comte $P$, Foucault $E$, Morin $D$, Hugli O. Task-shifting using a pain management protocol in an emergency care service: Nurses' perception through the eye of the Rogers's diffusion of innovation theory. Pain Manag Nurs. 2016;17(1):80-7.

54. Berben SA, Meijs TH, van Grunsven PM, Schoonhoven L, van Achterberg T. Facilitators and barriers in pain management for trauma patients in the chain of emergency care. Injury. 2012;43(9):1397-402.

55. Berben SA, Meijs TH, van Dongen RT, van Vugt AB, Vloet LC, Mintjes-de Groot JJ, et al. Pain prevalence and pain relief in trauma patients in the Accident \& Emergency department. Injury. 2008;39(5):578-85. 
56. Taylor DM, Chen J, Khan M, Lee M, Rajee M, Yeoh M, et al. Variables associated with administration of analgesia, nurse-initiated analgesia and early analgesia in the emergency department. Emerg Med J. 2017;34(1):13-9.

57. Jennings N, Kansal A, O'Reilly G, Mitra B, Gardner G. Time to analgesia for care delivered by nurse practitioners in the emergency department - a retrospective chart audit. Int Emerg Nurs. 2015;23(2):71-4.

58. Jennings N, Gardner G, O'Reilly G, Mitra B. Evaluating emergency nurse practitioner service effectiveness on achieving timely analgesia: a pragmatic randomized controlled trial. Acad Emerg Med. 2015;22(6):676-84.

59. De Chesnay M. Nursing research using ethnography: qualitative designs and methods in nursing. 1st ed. New York: Springer Publishing Company; 2014

60. DeWalt, K. and DeWalt, B., Participant observation: a guide for fieldworkers. 2002, Walnut Creek: AltaMira Press.

61. Schwartz-Barcott D, Patterson BJ, Lusardi P, Farmer BC. From practice to theory: tightening the link via three fieldwork strategies. J Adv Nurs. 2002;39(3):281-9.

62. Silverman D. Doing qualitative research. 3rd ed. London: Sage; 2012.

63. Kvale S, Brinkman S. Interviews: learning the craft of qualitative research interviewing. 2nd ed. London: Sage; 2009.

64. IBM. SPSS. California; 2015 .

65. QRS International Pty Ltd. NVivo. Burlington, USA; 2012.

66. Braun V, Clarke V. Using thematic analysis in psychology. Qual Res Psychol. 2006;3:77-101.

67. Shenton A. Strategies for ensuring trustworthiness in qualitative research projects. Educ Inform. 2004;22(2):63-75.

68. Creswell J, Plano Clark V. Designing and conducting mixed methods reseach. 2nd ed. London: Sage; 2010.

69. Teddlie C, Tashakkori A. Foundations of mixed methods research. California: SAGE publications; 2009 .

70. Greene J, Caracelli V. Advances in mixed methods evaluation: the challenges and benefits of integrating diverse paradigms. San Francisco: Jossey-Bass; 1989 .

71. Shaw EK, Ohman-Strickland PA, Piasecki A, Hudson SV, Ferrante JM, McDaniel RR Jr, et al. Effects of facilitated team meetings and learning collaboratives on colorectal cancer screening rates in primary care practices: a cluster randomized trial. Ann Fam Med. 2013;11(3):220-8. s1-8

72. Tashakkori A, Teddlie C. Mixed methodology: combining qualitative and quantitative approaches. Thousand Oaks: Sage; 1998.

73. Aarons GA, Wells RS, Zagursky K, Fettes DL, Palinkas LA. Implementing evidence-based practice in community mental health agencies: a multiple stakeholder analysis. Am J Public Health. 2009;99(11):2087-95.

74. Bryman A. Barriers to integrating quantitative and qualitative research. J Mixed Methods Res. 2007;1 (1):8-22.

75. Dellinger A, Leech N. Toward a unified validation framework in mixed methods research. J Mixed Methods Res. 2007;1 (4):309-32.

76. Silverman D. Effective qualitative research. Sydney: University of Technology; 2012.

77. Houghton C, Casey D, Shaw D, Murphy K. Rigour in qualitative case-study research. Nurse Res. 2013;20(4):12-7.

78. Onwuegbuzie AJ, Johnson RB, Collins KMT. Assessing legitimation in mixed research: a new framework. Qual Quant. 2011;45(6):1253-71.

79. Australian Government. National Statement on ethical conduct in human research. Canberra: National Health and Medical Research Council; 2015.

80. Curtis $L$, Morrell T. Pain management in the emergency department. Emerg Med Pract. 2006;8(7):1-28.

81. Erstad B, Puntillo K, Gilbert HG, Grap MJ, Li D, Medina J, Pasero C, et al. Pain management principles in the critically ill. Chest. 2009;135:1075-86.

82. Mulhall A. In the field: notes on observation in qualitative research. J Adv Nurs. 2003;41(3):306-13.

83. Varndell W, Fry M, Elliott D. Emergency nurses' perceptions of sedation management practices for critically ill intubated patients: a qualitative study. J Clin Nurs. 2015;24(21-22):1-10.

84. Varndell W, Fry M, Elliott D. A systematic review of observational pain assessment instruments for use with nonverbal intubated critically ill adult patients in the emergency department: an assessment of their suitability and psychometric properties. J Clin Nurs. 2016;26(1-2):7-32.

\section{Submit your next manuscript to BioMed Central and we will help you at every step:}

- We accept pre-submission inquiries

- Our selector tool helps you to find the most relevant journal

- We provide round the clock customer support

- Convenient online submission

- Thorough peer review

- Inclusion in PubMed and all major indexing services

- Maximum visibility for your research

Submit your manuscript at www.biomedcentral.com/submit
Biomed Central 